\title{
Slipped Upper Femoral Epiphysis; a rare clinical manifestation of MEN2: A Case Report
}

\author{
Slattery L., Crowley R., Doherty J., McKenna M, O' Shea D. \\ , Department of Endocrinology, St. Vincent's University Hospital, \\ Dublin
}

\section{AIM}

To examine the potential link between SUFE and MEN2A

\section{BACKGROUND}

TVIEN2 comprise a group of heritable disorders that result from mutations in the RET proto-oncogene on chromosome 101. MEN2A is characterised by medullary thyroid cancer, pheochromocytoma, and primary parathyroid hyperplasia. 40$50 \%$ develop phaeochromocytomas between the ages of $30 \& 40{ }^{2}$ The peak incidence of MTC in MEN2A is the 3 rd decade ${ }^{3}$. The incidence of primary hyperparathoridism. Hyperparathyroidism in MEN2A is often clinically occult ${ }^{4}$.

Slipped upper femoral epiphysis is a hip disorder in adolescence that occurs as a result of a Salter-Harris type physeal fracture; the proximal femoral epiphysis slips and is displaced relative to the metaphysis. The common clinical presentation is hip pain referring to the knee, decreased range of motion and antalgic gait ${ }^{5-} . U p$ to $50 \%$ of patients with SUFE are over the 95th percentile of weight for age..

\section{CASE REPORT}

The index case is a 49 year old female with a recent diagnosis of right pheochromocytoma on MIBG on a background of MEN2A. Her mother had a parathyroidectomy in 1976, a partial thyroidectomy in 1976 and bilateral pheochromocytomas in 1976 and 1983. The index case had a total thyroidectomy in 1980 at which time C cell hyperplasia was noted. Diagnosis was confirmed by RET oncogene mutation analysis. She has two sons and one daughter who are MEN2A positive. Her daughter was diagnosed with a pheochromocytoma in 2006 with a subsequent unilateral adrenelectomy.

There is a family history of slipped upper femoral epiphysis; she had a unilateral SUFE in her teens prior to her diagnosis of MEN2A; this diagnosis was initially missed. Her daughter underwent surgery for bilateral SUFE aged $11 \& 12$. Both the index case and her daughter did not fit the typical profile for a SUFE, and there was no history of trauma.

\section{DISCUSSION}

Primary hyperparathyroidism \& deranged thyroid function are recognised component of MEN2A. Prophylactic thyroidectomys are performed in children with RET germline mutations increasing their risk of hypothyroidism. It has been reported in the literature that endocrine disorders may contribute to abnormal growth plate development and mineralisation of cartilage and represent a significant risk factor for SUFE 6-7.

Complications of a SUFE include osteonecrosis, chondrolysis and osteoarthritis; prognosis is related to the severity of the slip \& early recognition.

\section{CONCLUSION}

Alterations of parathyroid hormone function in MEN2A may play a significant role in the development of SUFE in the susceptible adolescent population. A holistic approach to diagnosis may aid earlier patient identification.

\section{REFERENCES}

Frank-Raue K, Rondot S, Raue F (2010). Molecular genetics and phenomics of RET mutations: Impact on prognosis of MTC. Mol Cell Endocrinol; 322:2.

Machens A, Dralle H. Multiple endocrine neoplasia type 2 and the RET protooncogene: from bedside to bench to bedside. Mol Cell Endocrinol. 2006;247(1-2):34-40.

Brandi M.L., Gagel R.F., Angeli A (2001). Guidelines for diagnosis and therapy of MEN type 1 and type 2. J Clin Endocrinol Metab. ;86:5658-5671.

Multiple endocrine neoplasia type 2 (1994). Clinical

features and screening.Raue F, Frank-Raue K, Grauer A SOEndocrinol Metab Clin North Am. ;23(1):137

Hansson G, Nathorst-Westfelt J (2012). Management of the contralateral hip in patients with unilateral slipped upper femoral epiphysis. J Bone Joint Surg ;94:596-602

Puri R, Smith CS, Malhotra D, et al (1985). Slipped upper femoral epiphysis and juvenile hypothyroidism. J Bone Joint Surg;67:14-20.

Jingushi $S$ et al (1997) Deficienct of a PTH fragment containing the midportion of 1,25 dihydroxyvitamin $D$ in serum of patients with slipped capital femoral epiphysis $J$ pediatr Orthop. 17 (2):216 